\title{
Different outcomes of never-treated and treated patients with schizophrenia: 14-year follow-up study in rural China
}

Mao-Sheng Ran, Xue Weng, Cecilia Lai-Wan Chan, Eric Yu-Hai Chen, Cui-Ping Tang, Fu-Rong Lin, Wen-Jun Mao, Shi-Hui Hu, Yue-Qin Huang and Meng-Ze Xiang

\section{Background}

The long-term outcome of never-treated patients with schizophrenia is unclear.

\section{Aims \\ To compare the 14-year outcomes of never-treated and treated patients with schizophrenia and to establish predictors for never being treated.}

\section{Method}

All participants with schizophrenia $(n=510)$ in Xinjin, Chengdu, China were identified in an epidemiological investigation of 123572 people and followed up from 1994 to 2008

\section{Results}

The results showed that there were $30.6 \%, 25.0 \%$ and $20.4 \%$ of patients who received no antipsychotic medication in 1994, 2004 and 2008 respectively. Compared with treated patients, those who were never treated in 2008 were significantly older, had significantly fewer family members, had higher rates of homelessness, death from other causes, being unmarried, living alone, being without a caregiver and poor family attitudes. Partial and complete remission in treated patients $(57.3 \%)$ was significantly higher than that in the never-treated group (29.8\%). Predictors of being in the never-treated group in 2008 encompassed baseline nevertreated status, being without a caregiver and poor mental health status in 1994

\section{Conclusions}

Many patients with schizophrenia still do not receive antipsychotic medication in rural areas of China. The 14-year follow-up showed that outcomes for the untreated group were worse. Community-based mental healthcare, health insurance and family intervention are crucial for earlier diagnosis, treatment and rehabilitation in the community.

\section{Declaration of interest}

None.

\section{Copyright and usage}

(c) The Royal College of Psychiatrists 2015.
Previous international studies, including the best-designed World Health Organization (WHO) studies have reported that the outcome of schizophrenia is significantly more favourable in low- and middle-income countries than in high-income ones. ${ }^{1-5}$ However, given the methodological limitations of these studies, for example, the long-term outcome for never-treated patients with schizophrenia have not been explored, it may be premature to come to this conclusion. ${ }^{6-8}$ Many patients with schizophrenia in low- and middle-income countries received no treatment, and the outcome of this group may be poorer than that of those treated with antipsychotic drugs. ${ }^{6-7,9-11}$ Knowledge of psychopathology in untreated individuals would be helpful to identify the natural state of schizophrenia and improve understanding of the pathology underlying the illness. ${ }^{12}$ It is crucial therefore to explore the differences between patients with schizophrenia who have never been treated with those that have been treated with antipsychotic medications. ${ }^{13,14}$ Evidence shows that the longer psychotic symptoms proceed unchecked by medication the greater the likelihood of profound clinical deterioration. ${ }^{15}$ However, is there symptomatic remission in long-term outcome of nevertreated schizophrenia? A significant number of patients with schizophrenia are never-treated in low- and middle-income countries, especially in rural areas. ${ }^{7,9,16,17}$ It is only possible for studies of never-treated individuals with schizophrenia to be conducted in non-Western countries as in Western countries most patients will eventually be treated. ${ }^{9}$ In low- and middle-income countries this may be related to poor development of psychiatric services and low accessibility of the services, especially in rural areas. However, the clinical outcome of never-treated patients with schizophrenia and the reasons related to never-treated status are not well understood. ${ }^{7,12,16,17}$ Most previous studies on nevertreated patients with schizophrenia have been cross-sectional or short-term follow-up studies. ${ }^{9,11,12}$ However, longitudinal follow-up studies using large community samples are important to explore the different outcomes between never-treated and treated patients with schizophrenia. There are few with long-term (10 years) follow-up. ${ }^{7,9}$ Since the 1980s China has experienced dramatic social and economic development, which is reflected in the steady rise of the gross domestic product per capita. ${ }^{18}$ It is interesting to explore the impact of socioeconomic development on the treatment and outcome of patients with schizophrenia in the community. Our hypotheses were: the long-term outcome of those patients who were never treated is poorer than those treated with antipsychotic medication, and having no family caregiver will be the major reason for long-term never-treated status in patients with schizophrenia. The objectives of this 14-year prospective follow-up study were: (a) to compare the long-term outcomes of those individuals who were never treated with that of those who were treated; (b) to examine the differences between the groups who became treated and those who remained untreated over the 14-year follow-up; and (c) to define the predictors of long-term never-treated status in patients with schizophrenia.

\section{Method}

\section{Study population}

This is one of studies in the Chengdu Mental Health Project (CMHP) in Chengdu, China. All participants with schizophrenia $(n=510)$ were identified from an epidemiological investigation of 123572 people aged 15 years and older in six townships of Xinjin 
County, Chengdu in March 1994. Xinjin can be regarded as a typical rural county, in Southwest China. The six townships were randomly selected from all 14 townships of Xinjin County in the south of Chengdu. There is a psychiatric hospital (about 100 psychiatric beds) in Xinjin County. There was no national health insurance supporting patients' antipsychotic treatment. Participants were identified through screening procedures for psychosis (face-to-face interviews with the head of each household together with the key informant method) and general psychiatric interview. The details of this investigation have been described in previous publications. ${ }^{6,9,19}$ All participants lived in rural communities and met ICD-10 criteria $^{20}$ for a diagnosis of schizophrenia based on standardised administration of the Present State Examination (PSE) ${ }^{21}$ by trained research interviewers. ${ }^{19}$ Diagnostic reliability has been established. ${ }^{19}$ Of the 1994 sample, we followed up and interviewed $98.0 \%$ ( $n=500$ participants with schizophrenia and/or their key informants) 10 years later (May 2004) and 95.9\% ( $n=489) 14$ years later (June 2008). The study was approved by the University Committee on Human Research Subjects (CHRS) and all respondents gave informed consent at each stage of the study.

\section{Measurement}

The principal assessment tools were the PSE and Social Disability Screening Schedule (SDSS) 22 in the baseline investigation in 1994. ${ }^{19}$ The Positive and Negative Syndrome Scale (PANSS) ${ }^{23}$ and Global Assessment of Functioning (GAF ${ }^{24}$ were also used in $2008 .{ }^{25}$ After the training sessions, all the PANSS and GAF items between raters reached an acceptable level of reliability (kappa $(\kappa)>0.70)$. For participants still alive in 2004 and 2008, at least one person familiar with each participants' life and circumstances and the participant themselves were interviewed. For participants who had died, the next of kin or at least one person familiar with the participant were interviewed. All the interviews were conducted by trained psychiatrists using the Patients Follow-up Schedule (PFS) in 2004 and 2008..$^{6,25}$ The PFS was used to collect information concerning demographic characteristics, causes and time of death, clinical symptoms, treatment information, criminal behaviour, social functioning and social support. For all participants, medical and psychiatric treatment records were also obtained from hospitals, village doctors' clinics and traditional healers. For participants who had died, information from the death certification and suicide note, where applicable, was also obtained.

'Never treated' or 'remaining untreated' was defined as never or still not having received any antipsychotic medication before the investigation or follow-up. 'Treated' was defined as once having received antipsychotic medication before the investigation or follow-up. 'Became treated' was defined as not having received any antipsychotic medication before the investigation in 1994 and once having received antipsychotic medication during the follow-up from 1994 to 2004 or 2008. The classification of each death as being as a result of suicide, accident or natural causes represented the consensus opinion of interviewers and independent researchers after reviewing all information obtained during the interviews. Participants were defined as homeless and lost to follow-up if informants reported that they had wandered and slept in public places and that their whereabouts, at the time, were unknown. Participants were defined as being without a caregiver if they had no one (such as a family member, and others) to provide care (such as food, housing, financial support, treatment). Family economic status was defined according to the average family income. Criminal behaviour (for example theft, physical and sexual assault behaviours, and murder) was defined according to the reports of the participants and informants (such as relatives).
Participants were defined as in complete remission or partial remission if they had had no disorder-specific symptoms for 2 months or had an improvement in disorder-specific symptoms based on symptoms listed in the ICD-10.

\section{Statistical analysis}

We explored the link between baseline assessment (1994) and later evaluations (2004 and 2008) for never-treated and other variables. The differences between the never-treated and treated groups during the follow-up period (1994, 2004 and 2008) were assessed by comparing their demographic, psychological and social environment characteristics. A $\chi^{2}$-test was used to assess the significance of the differences in categorical data, and $t$-tests (two groups) or ANOVA (three groups) were used to compare between-group continuous factors. A logistic regression model was used to analyse the factors associated with never-treated status in 2008. Never-treated/remaining untreated or treated with antipsychotic medication during the follow-up period (1994-2008) was considered the dependent variable, whereas all the other variables from the 1994 evaluation (baseline data) were the independent variables. Statistical analyses were performed using SPSS Windows software (version 20.0).

\section{Results}

\section{Current status of the cohort}

Of the 510 people identified as having schizophrenia in 1994, 10 participants were excluded in $2004(n=500,98.0 \%)$ and 21 participants were excluded in $2008(n=489,95.9 \%)$ because they were lost to follow-up. The characteristics of the never treated and treated patients in 2008 are described in Table 1. Of the 489 patients who were followed up, $328(67.1 \%)$ were alive, 24 (4.9\%) had taken their own lives, $12(2.4 \%)$ died in accidental deaths, $85(17.4 . \%)$ died from other causes and $40(8.2 \%)$ were homeless. Among the 328 patients alive, 67 (20.4\%) had still never received antipsychotic medication during the follow-up period. The never-treated patients had significantly higher rates of death from other causes and homelessness, and significantly lower rate of survival than those treated. Among the 261 treated patients, there were 29 patients $(11.1 \%)$ who once took second-generation antipsychotics (such as clozapine or risperidone) in 2008.

\section{Characteristics of patients with schizophrenia alive in 1994, 2004 and 2008}

Table 2 shows the differences between never-treated/remaining untreated, became treated and treated patients in 1994, 2004 and 2008. Compared with treated patients, never-treated/remaining untreated patients were significantly older (1994, 2004, 2008), less likely to be married $(2004,2008)$, more likely to have no family caregiver and to live alone (1994, 2004, 2008), had a lower education level $(1994,2004)$ and fewer family members (1994, 2004, 2008). The treated patients had significantly higher rates of better family attitudes towards the patient $(1994,2008)$ than those never-treated and remaining untreated. Although the treated group had a significantly higher level of family economic status than the never-treated group in 1994, there were no differences in family economic status among the treated, became treated and remaining untreated groups in 2004 and 2008.

The never-treated or remaining untreated groups were significantly older at age at first onset than the treated patients (1994, 2004), had longer duration of illness than those in the became treated and treated groups (2004), had higher mean scores on the PANSS positive subscale and total score than became treated and treated groups (2008), and had higher mean scores on the 


\begin{tabular}{|c|c|c|c|c|}
\hline & \multirow{2}{*}{$\begin{array}{l}\text { Never-treated/remaining untreated } \\
\text { participants }(n=118)\end{array}$} & \multirow{2}{*}{$\begin{array}{l}\text { Treated participants } \\
\qquad(n=371)\end{array}$} & \multicolumn{2}{|c|}{ Statistics } \\
\hline & & & $\chi^{2}$ (d.f.) & $P$ \\
\hline Survivals, $n$ (\%) & $67(56.8)$ & $261(70.4)$ & $7.47(1)$ & $<0.01$ \\
\hline \multicolumn{5}{|l|}{ Deaths, $n$ (\%) } \\
\hline Suicide & $3(2.5)$ & $21(5.7)^{\mathrm{a}}$ & & 0.22 \\
\hline Accidental death & $2(1.7)$ & $10(2.7)^{\mathrm{a}}$ & & 0.74 \\
\hline Death due to other causes & $30(25.4)$ & $55(14.8)$ & $7.00(1)$ & $<0.01$ \\
\hline Homelessness & $16(13.6)$ & $24(6.5)$ & $5.99(1)$ & 0.01 \\
\hline
\end{tabular}

\begin{tabular}{|c|c|c|c|c|c|c|c|c|}
\hline & \multicolumn{2}{|c|}{ Participants, 1994} & \multicolumn{3}{|c|}{ Participants, 2004} & \multicolumn{3}{|c|}{ Participants, 2008} \\
\hline & $\begin{array}{l}\text { Never } \\
\text { treated } \\
(n=156)\end{array}$ & $\begin{array}{l}\text { Treated } \\
(n=354)\end{array}$ & $\begin{array}{l}\text { Remaining } \\
\text { untreated } \\
(n=93)\end{array}$ & $\begin{array}{l}\text { Became } \\
\text { treated } \\
(n=40)\end{array}$ & $\begin{array}{l}\text { Treated } \\
(n=239)\end{array}$ & $\begin{array}{l}\text { Remaining } \\
\text { untreated } \\
(n=67)\end{array}$ & $\begin{array}{l}\text { Became } \\
\text { treated } \\
(n=50)\end{array}$ & $\begin{array}{l}\text { Treated } \\
(n=211)\end{array}$ \\
\hline Male, $n(\%)$ & $81(51.9)$ & $156(44.1)$ & $44(47.3)$ & $15(37.5)$ & $100(41.8)$ & 29 (43.3) & $18(36.0)$ & $84(39.8)$ \\
\hline Married, $n(\%)$ & $107(68.6)$ & $261(73.7)$ & $42(45.2)$ & $28(70.0)$ & $168(70.3)^{\star *}$ & $34(50.7)$ & $31(62.0)$ & $144(68.2)^{*}$ \\
\hline Family economic status, <mean: $n(\%)$ & $96(61.5)$ & $182(51.4)^{*}$ & $53(57.0)$ & $24(60.0)$ & $128(53.6)$ & $53(79.1)$ & $34(68.0)$ & $146(69.2)$ \\
\hline Education, primary school: $n$ (\%) & $127(81.4)$ & $245(69.2)^{\star *}$ & $76(81.7)$ & $27(67.5)$ & $159(66.5)^{\star *}$ & $51(76.1)$ & $40(80.0)$ & $139(65.9)$ \\
\hline Living alone, $n(\%)$ & $35(22.4)$ & $29(8.2)^{\star * *}$ & $26(28.0)$ & $3(7.5)$ & $36(15.1)^{\star *}$ & $20(29.9)$ & $7(14.0)$ & $22(10.4)^{\star *}$ \\
\hline With a family caregiver, $n(\%)$ & $116(74.4)$ & $304(85.9)^{\star *}$ & $77(82.8)$ & $39(97.5)$ & $220(92.1)^{*}$ & $58(86.6)$ & $47(94.0)$ & $203(96.2)^{*}$ \\
\hline $\begin{array}{l}\text { Families' attitude towards patient, } \\
\text { maltreatment: } n(\%)\end{array}$ & $69(44.2)$ & $91(25.7)^{\star * *}$ & & & & $24(35.8)$ & $12(24.0)$ & $38(18.0)^{*}$ \\
\hline Criminal behaviour, $n(\%)$ & $8(5.1)$ & $10(2.8)$ & & & & $9(13.4)$ & $6(12.0)$ & $23(10.9)$ \\
\hline \multicolumn{9}{|l|}{ Mental status, $n(\%)$} \\
\hline Complete remission & $15(9.6)$ & $110(31.1)^{\star \star *}$ & & & & $11(16.4)$ & $9(18.0)$ & $72(34.1)^{* *}$ \\
\hline Partial remission & $12(7.7)$ & $56(15.6)$ & & & & $9(13.4)$ & $13(26.0)$ & $49(23.2)$ \\
\hline Marked symptoms or deteriorated & $129(82.7)$ & $188(53.1)$ & & & & $47(70.2)$ & $28(56.0)$ & $90(42.7)$ \\
\hline Inability to work, $n(\%)$ & $34(21.8)$ & $63(17.8)$ & $25(26.9)$ & $12(30.0)$ & $47(19.7)$ & $24(35.8)$ & $19(38.0)$ & $51(24.2)$ \\
\hline Age, years: mean (s.d.) & $48.2(15.2)$ & $43.0(15.3)^{\star \star *}$ & $57.8(14.6)$ & $50.7(11.8)$ & $50.4(12.6)^{* * *}$ & $60.2(12.3)$ & $57.0(12.5)$ & $54.5(12.8)^{\star \star *}$ \\
\hline Number of family members, mean (s.d.) & $3.1(1.6)$ & $3.6(1.4)^{\star \star \star}$ & $2.9(1.8)$ & $3.5(1.3)$ & $3.7(1.4)^{\star \star}$ & $2.6(1.6)$ & $3.3(1.6)$ & $3.4(1.6)^{* *}$ \\
\hline Duration of illness, years: mean (s.d.) & $13.7(12.2)$ & $11.9(10.8)$ & 24.9 (13.3) & $18.9(9.0)$ & $20.8(9.6)^{* *}$ & $26.7(11.1)$ & $25.0(12.7)$ & $25.1(10.4)$ \\
\hline Age at first onset, years: mean (s.d.) & $34.1(13.7)$ & $29.7(12.4)^{* * *}$ & $31.8(12.7)$ & $31.3(11.8)$ & $28.1(10.8)^{*}$ & $32.1(12.4)$ & $28.9(9.8)$ & $28.5(10.6)$ \\
\hline \multicolumn{9}{|l|}{ PANSS, mean (s.d.) } \\
\hline Total positive score & & & & & & $13.8(6.0)$ & $12.0(6.0)$ & $11.6(5.9)^{*}$ \\
\hline Total negative score & & & & & & $17.5(9.8)$ & $18.5(8.9)$ & $14.0(8.7)^{\star * *}$ \\
\hline Total general mental score & & & & & & $28.8(10.3)$ & $27.0(8.3)$ & $24.7(9.2)^{*}$ \\
\hline Total score & & & & & & $63.3(21.6)$ & $59.1(19.3)$ & $53.4(21.9)^{*}$ \\
\hline Total score of GAF & & & & & & $57.0(24.0)$ & $55.4(23.0)$ & $64.3(25.0)^{*}$ \\
\hline
\end{tabular}

PANSS negative subscale and general mental scores than treated patients (2008). There were no significant differences of mean scores on the PANSS negative subscale and general mental scores between the remaining untreated and became treated groups (2008). The rates of remission and partial remission were significantly higher in the treated patients $(46.7 \%$ in 1994 and $57.3 \%$ in 2008) than the never treated or remaining untreated patients $(17.3 \%$ in 1994 and $29.8 \%$ in 2008$)(P<0.01)$. The total mean scores on the GAF were significantly higher in the treated group than the remaining untreated and became treated groups in 2008. There were no significant differences in the rates unable to work among the never-treated or remaining untreated, became treated and treated groups.

\section{Predictors of the never-treated/remaining untreated status of patients in 2008}

Table 3 shows the multivariate mode of predictors of the nevertreated/remaining untreated status of patients in 2008 (logistic regression analyses). Three factors were identified as significantly independent predictors of the never-treated status of patients in 2008: never-treated status, without caregiver and poor mental health status in 1994.

\section{Discussion}

To our knowledge, this is the first 14-year prospective cohort study of outcome in people with schizophrenia who had never been treated with antipsychotic medication in a rural community. This study contributes to the existing knowledge on the long-term natural outcome of untreated patients with schizophrenia. The strengths of this study include the use of a large representative community sample in rural China, its longitudinal 14-year follow-up data and high rates of participant retention.

\section{Status of never-treated patients}

The results of this study showed that $30.6 \%$ of patients with schizophrenia had never been treated in 1994, which is consistent 


\begin{tabular}{|c|c|c|c|}
\hline & Wald & OR $(95 \% \mathrm{Cl})$ & $P$ \\
\hline Never treated in 1994 & 14.681 & $3.354(1.806-6.230)$ & $<0.001$ \\
\hline Without caregiver in 1994 & 9.699 & $4.030(1.676-9.690)$ & 0.002 \\
\hline Poor mental health status in 1994 & 8.696 & $1.912(1.243-2.941)$ & 0.003 \\
\hline
\end{tabular}

with a study in an Indian urban community. ${ }^{16}$ There were still $25.0 \%$ and $20.4 \%$ of patients with schizophrenia who had not been treated with antipsychotic medication in 2004 and 2008 respectively. Although the results of Cox hazard regression analyses did not support differences in mortality between never-treated/ remaining untreated and treated patients with schizophrenia in our previous 10 -year follow-up study in $2004,{ }^{7}$ the results of this 14-year follow-up still showed that never-treated/remaining untreated patients with schizophrenia had significantly higher rates of death from other causes and homelessness, and lower rate of survivals than treated patients. There were no significant differences in suicide and accidental death rate between never-treated/remaining untreated and treated patients. The results indicate that nevertreated/remaining untreated patients may have a poor long-term outcome (for example higher rates of death and homelessness) than treated patients. ${ }^{1,7}$

\section{Differences between never-treated/remaining untreated, became treated and treated patients}

There were no significant differences of gender among nevertreated/remaining untreated, became treated and treated patients with schizophrenia, which is consistent with previous studies. ${ }^{16}$ Compared with treated patients, the results of this study showed that never-treated/remaining untreated patients were more likely to be older in age and had a later age at onset of illness, which is also consistent with our previous study and a study in India. ${ }^{7,16}$ Although the level of education was related to the never-treated/ remaining untreated status in 1994 and 2004, which is consistent with a study in India, ${ }^{16}$ there was no significant relationship between the level of education and remaining untreated status in 2008 .

The results of this study show that never-treated/remaining untreated patients were more likely to be single, live alone and have no family caregiver and fewer family members than the became treated and treated groups (2004 or 2008). The rate of being married in never-treated/remaining untreated patients reduced gradually from $68.6 \%$ in 1994 to $50.7 \%$ in 2008 . The results of this study show that that marriage and a family caregiver are crucial for better antipsychotic treatment status in patients with schizophrenia, which is consistent with previous studies. ${ }^{9,26,27}$ Marriage and a family caregiver may be related to positive help-seeking behaviour; family members can provide a very effective umbrella of care and protection for patients with severe mental illness with resulting better outcomes. ${ }^{11,27,28}$ The results of a study in rural Ethiopia even showed that living in a household with three or more adults predicted complete remission. ${ }^{11}$ However, the results of an Indian study indicated that never-treated patients with schizophrenia were more often living with larger extended/joint families. ${ }^{16}$ This may indicate cultural differences in various countries.

The results of this study showed that never-treated/remaining untreated patients had significantly lower rates of symptomatic complete remission (9.6\% in 1994 and $16.4 \%$ in 2008) than those treated with antipsychotic medication $(31.1 \%$ in 1994 and $34.1 \%$ in 2008), which is consistent with previous studies. ${ }^{4,7}$ The results of this study support the suggestion that the long-term course of schizophrenia is more heterogeneous, with a significant portion of patients exhibiting remission. ${ }^{29,30}$ The results of this study also indicate that never-treated/remaining untreated patients with schizophrenia have poorer long-term mental status and more psychotic symptoms (for example in terms of PANSS scores), especially positive and negative symptoms, than treated patients, consistent with previous studies in India, Bali and our studies. ${ }^{7,9,16,17,31}$ Moreover the became treated patients have relatively less psychotic symptoms (for example in terms of PANSS positive subscale and total scores) than never-treated/remaining untreated patients. The results of this study support the suggestion that the natural course of schizophrenia, in terms of clinical outcome, death and homelessness, is poor in Chinese rural areas. ${ }^{7,9}$ Given the poor outcome of never-treated/remaining untreated patients, the results of this study also support the suggestion that the outcome of schizophrenia in low- and middle-income countries is heterogeneous and may not be better than that in high-income countries. $1,6,8,11$

Evidence suggests that early intervention with antipsychotic medication may be a significant predictor of and play a substantial role in improving long-term remission and outcomes. ${ }^{29,32-34}$ The longer psychotic symptoms continue unchecked by medication, the greater the likelihood of profound clinical deterioration. ${ }^{15} \mathrm{~A}$ critical 'window of opportunity' during early treatment should be targeted with high-quality integrated care..$^{35,36}$ The results of Harrow and colleagues' 20-year study of patients admitted once to hospital indicate that, longitudinally, after the first few years, antipsychotic medications do not eliminate or reduce the frequency of psychosis in schizophrenia. ${ }^{37}$ The results of our study among patients in a rural community signified that antipsychotic medication and medication adherence should be crucial for controlling psychotic symptoms, ${ }^{1,7,11,38-41}$ especially positive and negative symptoms in long-term follow-up. The reason for the effectiveness in controlling psychotic symptoms in patients with schizophrenia may be related to the common use of antipsychotics, especially first-generation antipsychotics in rural China. Further studies need to be conducted on this issue.

The results of this study showed that there were no differences in the ability to work in the remaining untreated, became treated and treated groups, but the treated patients had significantly higher social functioning (for example in terms of GAF scores) than the remaining untreated and became treated patients with schizophrenia in the 14-year follow-up. In an Indian study, never-treated patients were also found to be more severely disabled than those who had been treated. ${ }^{16}$ The results of our study also showed that even though $70.2 \%$ of never-treated patients still retained marked symptoms or deteriorated, $64.2 \%$ of these patients could still do full- or part-time work in the 14-year follow-up. This result supports the suggestion that any decrease in ability to work caused by the illness may not correspond to the severity of the symptoms of the illness, consistent with our previous 2 -year follow-up study. ${ }^{9}$ Patients with schizophrenia in rural China may have greater opportunities to use their capacities for work (such as general housework, farm work). ${ }^{42,43}$ Evidence indicates that functional outcome is not only related to the disease itself, but also to common social and economic barriers. ${ }^{44}$ The reasons may also include (a) antipsychotic medication can not improve social functioning in patients with schizophrenia, and (b) patients' social functioning may be poor in both treated and never-treated groups as the longterm (for example 14-year) course of illness. The results of our study support the need for specialised functional treatment and support programmes for the majority of patients with schizophrenia. ${ }^{24,36}$ 


\section{Predictors of the never-treated/remaining untreated status of patients in the 14-year follow-up}

Why have patients with schizophrenia remained untreated in the 14-year follow-up? The results of this study indicated that the main predictors of the never-treated/remaining untreated status of patients in 2008 included baseline never-treated status, being without a family caregiver and poor mental health status in 1994. Even though a poor family economic status was related to the never-treated status in 1994, there was no relationship between family economic status and never-treated/remaining untreated status in 2004 and 2008. Although having extended families in low- and middle-income countries may not necessarily enhance chances of accessing care, ${ }^{41,45}$ the results of our study support the suggestion that the family plays a major role in patient's treatment and management in rural China, and the nevertreated/remaining untreated status of patients is associated with fewer family caregivers in rural China. ${ }^{7,46}$ We suggest that the traditionally supportive family network may be broken down by prolonged illness and patients' poor clinical status. ${ }^{19}$ Although the likelihood of receiving treatment may be higher if patients have more severe symptoms, ${ }^{47}$ the present study demonstrates that the long-term never-treated/ remaining untreated status in patients with schizophrenia is also related to patients' poor clinical condition, consistent with a study in Bali and our previous study. ${ }^{7,17}$

\section{Implications for services}

Our findings indicate that the full remission rates for nevertreated/remaining untreated and treated patients with schizophrenia were $16.4 \%$ and $34.1 \%$, respectively, in the 14 -year follow-up. The results of this study support the suggestion that never-treated/remaining untreated patients have a poorer long-term outcome than those treated with antipsychotic medication. ${ }^{7,41}$ Treated patients also have a better outcome than those patients in the became treated with antipsychotic medication group. This may indicate the importance of early antipsychotic medication. The reasons for poorer long-term outcome in the never-treated/ remaining untreated group in rural China may include (a) a lack of antipsychotic medications, (b) a lack of family caregivers, and (c) a high rate of poor attitudes and care from families. Lack of family caregivers and a high rate of poor attitudes and care from families may influence patients' access to antipsychotic medications and social functioning. Our findings emphasise the importance of antipsychotic medication, especially at an early stage of illness for good long-term outcomes. ${ }^{7,11,39}$ Given the importance of antipsychotic medication for individuals with schizophrenia, improving medication access and minimising duration of untreated psychosis are important strategies that should be addressed in China and other low- and middle-income countries. Early intervention for schizophrenia, including psychosocial intervention and medication, should be emphasised for patients with schizophrenia. ${ }^{9,46}$

Our results have implications for improving the treatment of never-treated/remaining untreated patients in China and elsewhere. Long-term outcomes of schizophrenia may be worsened as the absence of mental health services delays treatment. Knowledge of different outcomes between never-treated/remaining untreated and treated people with schizophrenia may change the attitudes of people and their families towards medication and improve the rates of antipsychotic medication. ${ }^{7}$ Although there has been dramatic socioeconomic development in China in the past three decades, ${ }^{18}$ many patients with schizophrenia still do not receive any medication in rural areas. Resources and services for mental illness are insufficient considering the burden caused by these disorders around the world. What is the best way to solve this important basic treatment issue for these patients in rural China? It is crucial to (a) provide social welfare, health insurance and mental healthcare for patients with schizophrenia, especially those without family caregivers, (b) promote public education to reduce stigma about mental illness and cultivate positive attitudes in family members towards patients with schizophrenia, and (c) strengthen community-based mental health services to provide earlier diagnosis, antipsychotic treatment, mental rehabilitation, and family and caregiver support. ${ }^{7,46}$

The results of our 10- and 14-year studies among people with schizophrenia challenge the axiom in international psychiatry that schizophrenia has a better course and outcome in low- and middle-income countries. ${ }^{5,7,9}$ Given the high rates of mortality, homelessness and never-treated patients with schizophrenia in low- and middle-income countries, it is premature to come to this conclusion if withdrawals or attrition because of deaths and homelessness and the outcome of many never-treated individuals are not included in the follow-up analyses. ${ }^{6-8}$ Given the representative sample used in the 14 -year follow-up study, we suggest that our findings are generalisable to the population with schizophrenia in rural areas, and even other low- and middleincome countries that have a similar social environment. Overall, mortality, homelessness and severe clinical symptoms are serious concerns in never-treated/remaining untreated and treated individuals with schizophrenia in rural China.

\section{Limitations}

The limitations of this study include possible recall bias in interviews with participants and informants at long-term follow-up intervals, but this bias may be minimised by the use of multiple follow-up data sources. The death and suicide rates may be underestimated because most homeless individuals were lost to follow-up. Given the diversity of sociocultural, economic and care provision characteristics, the results of this rural China study may not generalise to urban areas and high-income countries.

Mao-Sheng Ran, MMed, PhD, Xue Weng, BSW, Cecilia Lai-Wan Chan, PhD, Department of Social Work and Social Administration, University of Hong Kong, Hon Kong; Eric Yu-Hai Chen, MD, Department of Psychiatry, University of Hong Kong, Hong Kong; Cui-Ping Tang, RN, Fu-Rong Lin, MD, Xinjin Mental Hospital, Xinjin, Chengdu, China; Wen-Jun Mao, MD, Shi-Hui Hu, MD, Chengdu Mental Health Center, Chengdu, China; Yue-Qin Huang, PhD, institute of Mental Health, Peking Center, Beijing China; Meng-Ze Xiang, MD, Department of Psychiatry, Sichuan University, China

Correspondence: Mao-Sheng Ran, MMed, PhD, Department of Social Work and Social Administration, University of Hong Kong, Hong Kong, China. Email: msran@hku.hk

First received 16 Sep 2014, final revision 18 Jan 2014, accepted 21 Jan 2015

\section{Funding}

The 1994 Chengdu study was supported by a grant from the China Medical Board in New York (CMB, 92-557; M.-Z.X., principal investigator). This study was supported in part by Global Research Initiative Program from National Institutes of Health (NIH, 1R01 TW007260-01; M.-S.R., principal investigator) and American Foundation for Suicide Prevention (AFSP; M.-S.R., principal investigator).

\section{Acknowledgement}

The authors thank the Chengdu Mental Health Center and the Xinjin Mental Hospital for collaboration and data collection.

\section{References}

1 Harrison G, Hopper K, Craig T, Laska E, Siegel C, Wanderling J, et al. Recovery from psychotic illness: a 15- and 25-year international follow-up study. Br J Psychiatry 2001; 178: 506-17. 
2 Jablensky A, Sartorius N, Ernberg G, Anker M, Korten A, Cooper JE, et al Schizophrenia: manifestations, incidence, and course in different cultures. A World Health Organization ten-country study. Psychol Med Monogr Supp 1992; 20: 1-97.

3 Sartorius N, Gulbinat W, Harrison G, Laska E, Siegel C. Long-term follow-up of schizophrenia in 16 countries. A description of the international study of schizophrenia conducted by the World Health Organization. Soc Psychiatry Psychiatr Epidemiol 1996; 31: 249-58.

4 Craig TJ, Siegel C, Hopper K, Lin S, Sartorius N. Outcome in schizophrenia and related disorders compared between developing and developed countries. A recursive partitioning re-analysis of the WHO DOSMD data. Br J Psychiatry 1997; 170: 229-33.

5 Mueser KT, McGurk SR. Schizophrenia. Lancet 2004; 363: 2063-72.

6 Ran MS, Chen EYH, Conwell Y, Chan CLW, Yip PSF, Xiang MZ, et al. Mortality in people with schizophrenia in rural China: 10-year cohort study. Br J Psychiatry 2007; 190: 237-42.

7 Ran MS, Chan CLW, Chen EYH, Mao WJ, Hu SH, Tang CP, et al. Differences in mortality and suicidal behaviour between treated and never-treated persons with schizophrenia in rural China. Br J Psychiatry 2009; 195: 126-31.

8 Cohen A, Patel V, Thara R, Gureje O. Questioning an axiom: better prognosis for schizophrenia in the developing world? Schizophr Bull 2008; 34: 229-44.

9 Ran MS, Xiang MZ, Huang MS, Shan YH. Natural course of schizophrenia: two-year follow-up study in a rural Chinese community. Br J Psychiatry 2001 178: $154-8$.

10 Demyttenaere K, Bruffaerts R, Posada-Villa J, Gasquet I, Kovess V, Lepine JP, et al. Prevalence, severity, and unmet need for treatment of mental disorders in the World Health Organization World Mental Health Surveys. JAMA 2004; 291: 2581-90.

11 Alem A, Kebede D, Fekadu A, Shibre T, Fakadu D, Beyero T, et al. Clinical course and outcome of schizophrenia in a predominantly treatment - naive cohort in rural Ethiopia. Schizophr Bull 2009; 35: 646-54.

12 Tirupati SN, Padmavati R, Thara R, McCreadie RG. Psychopathology in never-treated schizophrenia. Compr Psychiatry 2006; 47: 1-6.

13 Dohrenwend BP, Dohrenwend BS. Perspectives on the past and future of psychiatric epidemiology. Am J Public Health 1982; 72: 1271-9.

14 Torrey EF. Studies of individuals with schizophrenia never treated with antipsychotic medications: a review. Schizophr Res 2002; 58: 101-15.

15 Black K, Peters L, Rui Q, Milliken H, Whitehorn D, Kopala LC. Duration of untreated psychosis predicts treatment outcome in an early psychosis program. Schizophr Res 2001; 47: 215-22.

16 Padmavathi R, Rajkumar S, Srinivasan TN. Schizophrenic patients who were never treated - a study in an Indian urban community. Psychol Med 1998; 28: 1113-7.

17 Kurihara T, Kato M, Reverger R, Tirta IGR, Kashima H. Never-treated patients with schizophrenia in the developing country of Bali. Schizophr Res 2005; 79 307-13.

18 World Bank. GDP per capita. World Bank, 2013 (http://data.worldbank.org/ indicator/NY.GDP.PCAP.CD)

19 Ran MS, Xiang MZ, Li SX, Shan YH, Huang MS, Li SG, et al. Prevalence and outcome of schizophrenia in a Chinese rural area: an epidemiological study Aust NZ J Psychiatry 2003; 37: 452-7.

20 World Health Organization. The ICD-10 Classification of Mental and Behavioural Disorders: Clinical Descriptions and Diagnostic Guidelines. WHO 1992.

21 Wing JK, Cooper JE, Sartorius N. The Measurement and Classification of Psychiatric Symptoms. Cambridge University Press, 1974.

22 Liu JQ, Wang CH. Social Disability Screening Schedule (SDSS). In Handbook of Mental Illness Epidemiological Investigation (eds YC Shen, CH Wang): 60-7. People Health Press, 1985.

23 Kay SR, Fiszbein A, Opler A. The Positive and Negative Syndrome Scale (PANSS) for schizophrenia. Schizophr Bull 1987; 13: 261-76.

24 American Psychiatric Association. Diagnostic and Statistical Manual of Mental Disorders (4th edn, text revision) (DSM-IV-TR). APA, 2000.

25 Ran MS, Chen PY, Liao ZG, Chan CLW, Chen EYH, Tang CP, et al. Criminal behavior among persons with schizophrenia in rural China. Schizophr Res 2010; 122: 213-8.
26 Sartorius N, Jablensky A, Shapiro R. Two-year follow-up of the patients included in the WHO international pilot study of schizophrenia. Psychol Med 1977; 7: 529-41.

27 Thara R, Srinivasan TN. Outcome of marriage in schizophrenia. Soc Psychiatry Psychiatr Epidemiol 1997; 32: 416-20.

28 Leff J, Wig NN, Bedi H, Menon DK, Kuipers L, Korten A, et al. Relatives expressed emotion and the course of schizophrenia in Chandigarh. A two-year follow-up of a first-contact sample. Br J Psychiatry 1990; 156: 351-6.

29 Bellack AS. Scientific and consumer models of recovery in schizophrenia: concordance, contrasts, and implications. Schizophr Bull 2006; 32: 432-42.

30 Jobe TH, Harrow M. Long-term outcome of patients with schizophrenia: a review. Can J Psychiatry 2005; 50: 892-900.

31 Murthy RS, Kishore KV, Chisholm D, Thomas T, Sekar K, Chandrashekari CR. Community outreach for untreated schizophrenia in rural India: a follow-up study of symptoms, disability, family burden and costs. Psychol Med 2005 35: 341-51.

32 Wyatt RJ. Neuroleptics and the natural course of schizophrenia. Schizophr Bull 1991; 17: 325-51.

33 Bottlender R, Sato $T$, Jager M, Wegner U, Wittmann J, Strauss A, et al. The impact of the duration of untreated psychosis prior to first psychiatric admission on the 15-year outcome in schizophrenia. Schizophr Res 2003; 62: $37-44$.

34 Kurihara $T$, Kato $M$, Reverger R, Tirta IGR. Remission in schizophrenia: a community-based 6-year follow-up study in Bali. Psychiatry Clin Neurosci 2011; 65: 476-82.

35 Emsley R, Rabinowttz J, Medori R, Early Psychosis Global Working Group. Remission in early psychosis: rates, predictors, and clinical and functional outcome correlates. Schizophr Res 2007; 89: 129-39.

36 Lambert M, Naber D, Schacht A, Wagner T, Hundemer HP, Karow A, et al. Rates and predictors of remission and recovery during 3 years in 392 nevertreated patients with schizophrenia. Acta Psychiatr Scand 2008; 118: 220-9.

37 Harrow M, Jobe TH, Faull RN. Does treatment of schizophrenia with antipsychotic medications eliminate or reduce psychosis? A 20-year multifollow-up study. Psychol Med 2014; 44: 3007-16.

38 Fenton WS, Blyler CR, Heinssen RK. Determinants of medication compliance in schizophrenia: empirical and clinical findings. Schizophr Bull 1997; 23: 637-51.

39 Wunderink A, Nienhuis F, Systema S, Wiersma D. Treatment delay and response rate in first episode psychosis. Acta Psychiatr Scand 2005; 113: 332-9.

40 Novick D, Haro JM, Suarez D, Lambert M, Lépine JP, Naber D. Symptomatic remission in previously untreated patients with schizophrenia: 2-year results from the SOHO study. Psychopharmacol 2007; 191: 1015-22.

41 Tirupati NS, Rangaswamy T, Raman P. Duration of untreated psychosis and treatment outcome in schizophrenia patients untreated for many years. Aust NZ J Psychiatry 2004; 38: 339-43.

42 Ran MS, Chen S, Chen EY, Ran BY, Tang CP, Lin FR, et al. Risk factors for poor wok functioning of persons with schizophrenia in rural China. Soc Psychiatry Psychiatr Epidemiol 2011; 46: 1087-93.

43 Yang LH, Phillips MR, Li X, Yu G, Zhang J, Shi Q, et al. Employment outcome for people with schizophrenia in rural v. urban China: population-based study. Br J Psychiatry 2013; 203: 272-9.

44 Marwaha S, Johnson S. Schizophrenia and employment. Soc Psychiatry Psychiatr Epidemiol 2004; 39: 337-49.

45 Srinivasan TN, Thara R. How do men with schizophrenia fare at work? A follow-up study from India. Schizophr Res 1997; 25: 149-54.

46 Ran MS, Xiang MZ, Chan CLW, Leff J, Simpson P, Huang MS, et al. Effectiveness of psychoeducational intervention for rural Chinese families experiencing schizophrenia: a randomized controlled trial. Soc Psychiatry Psychiatr Epidemiol 2003; 38: 69-75.

47 Wing JK, Bebbington P, Hurry J, Tennant C. The prevalence in the general population of disorders familiar to psychiatrists in hospital practice. In What is a case (eds JK Wing, P Bebbington, LN Robins): 46-61. Grant McIntyre, 1981. 